\title{
Studies on the Metabolic Fate of Lamivudine (I): Absorption, Metabolism and Excretion of Lamivudine in Rats
}

\author{
Takatoshi Takubo, Takahito MoriYa, Seiji HiRAyama, \\ Yoshiyuki Minamide, Toshihiro Kato, Ryoko NaKamura, Junji Kinami \\ ADME Section, Pre-clinical Research Department, Tsukuba Research Laboratories, Nippon Glaxo Ltd., Ibaraki
}

\begin{abstract}
Summary: The absorption, metabolism and excretion of nucleoside analogue, lamivudine, were investigated after a single oral administration of ${ }^{3} \mathrm{H}$-lamivudine to rats at a dose of $2 \mathrm{mg} / \mathrm{kg}$.

1. The total radioactivity in plasma reached the maximum at about 1 hour after oral administration, and declined rapidly with a half-life of about 2 hours. The absorption of ${ }^{3} \mathrm{H}$-lamivudine after oral administration was slightly decreased by feeding. ${ }^{3} \mathrm{H}$-lamivudine was well absorbed in each site of small intestine but not stomach.

2. The concentrations of unchanged drug in plasma reached the maximum within 1 hour after oral administration of lamivudine at $2 \mathrm{mg} / \mathrm{kg}$, and declined rapidly with a half-life of about 1 hour. The bioavailability accounted for $81.9 \%$ and $76.7 \%$ in male and female rats, respectively. Significant linearity of AUC was observed at the dose range of 2 to $10 \mathrm{mg} / \mathrm{kg}$ in male rats.

3. The excreted radioactivity in male and female rats was $69.3 \%$ and $74.1 \%$ of the dose in urine and $29.1 \%$ and $23.7 \%$ in feces, respectively, up to 168 hours after oral administration. The majority of the dosed radioactivity was excreted into urine within 24 hours post dose. Less than $1 \%$ of the dose was recovered in the bile within 48 hours post dose.

4. Radio-HPLC analysis of the collected urine indicated that virtually all of the radioactivity in the urine consisted of the unchanged lamivudine.
\end{abstract}

Key words: Lamivudine, Rats, Absorption, Metabolism, Excretion

\section{Introduction}

Lamivudine, ((2R-cis)-4-amino-1-(2-hydroxymethyl-1,3-oxathiolan-5-yl)-(1H)-pyrimidin-2-one), is a cytosine dideoxy-nucleoside analogue and reported to inhibit human immunodeficiency virus (HIV) and hepatitis B virus (HBV) DNA replication. ${ }^{1-4)}$ Lamivudine is currently being developed/marketed as an antiviral agent for HIV (Epivir[3TC]) and also is being developed for human HBV by Glaxo Wellcome, UK.

In this study, absorption, metabolism and excretion of lamivudine were investigated after a single oral administration of tritium labeled lamivudine ( ${ }^{3} \mathrm{H}$-lamivudine) to rats, in order to elucidate the disposition of lamivudine in rats.

\section{Materials and Methods}

\section{Chemicals}

${ }^{3} \mathrm{H}$-lamivudine was supplied by Glaxo Wellcome Research and Development, UK. The structure and labeled position of ${ }^{3} \mathrm{H}$-lamivudine is shown in Fig. 1. The specific activity was $451 \mathrm{GBq} / \mathrm{mmol}$ and the radiochemical purity was more than $96 \%$ accounted by high performance liquid chromatographic (HPLC) analysis using an ODS column (Ultron VX-ODS; Shinwa Chemical Industries) and $5 \%(\mathrm{v} / \mathrm{v})$ acetonitrile in $10 \mathrm{mM}$ potassium dihydrogenphosphate as mobile phase.

Non-labeled lamivudine and stereoisomeric sulphoxides of lamivudine (GI138868X (cis form) and GI138870X (trans form, Fig. 1) were also supplied by Glaxo Wellcome Research and Development, UK. All other chemicals were of reagent grade.

\section{Animals}

Male and female Wistar rats at $7-8$ weeks age (Charles River Japan) were used. The rats were fed standard laboratory diet (MF, Oriental Yeast Co. Ltd.) and water ad libitum. Environmental conditions were always controlled at $23 \pm 3^{\circ} \mathrm{C}$ for temperature and $55 \pm 15 \%$ for relative humidity. Rats receiving oral dose were fasted overnight prior to dosing and for further 4 hours after dosing, except for the study to examine the dietary effect to pharmacokinetics of total radioactivity.

\section{Administration of the Drug}

${ }^{3} \mathrm{H}$-lamivudine was dissolved in distilled water for oral dose and in sterile saline for intravenous dose. The ${ }^{3} \mathrm{H}-$ lamivudine was diluted by non-labeled lamivudine. Each 


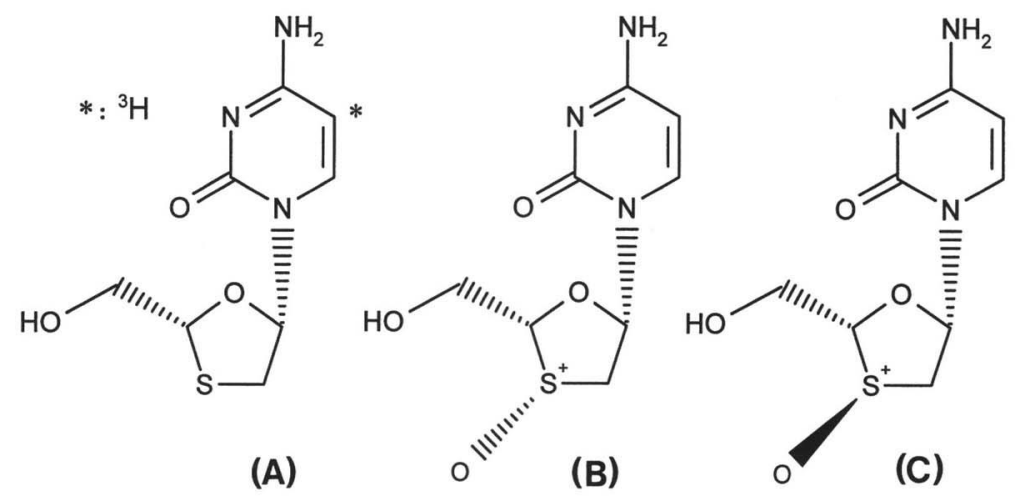

Fig. 1 Chemical structures of ${ }^{3} \mathrm{H}$-lamivudine (A), GI138868X (B) and GI138870X (C).

rat received the drug solution as a single oral or intravenous dose equivalent to $2 \mathrm{mg} / \mathrm{kg}$ body-weight. The radiolabeled doses and volumes administered were about 3.7 $\mathrm{MBq} / 4 \mathrm{ml} / \mathrm{kg}$ for oral dose, $3.7 \mathrm{MBq} / 2 \mathrm{ml} / \mathrm{kg}$ for intravenous dose.

For determination of unchanged drug in plasma, the non-labeled lamivudine was administered to separate groups of rats at 2, 5 and $10 \mathrm{mg} / \mathrm{kg}$ for oral dose, $2 \mathrm{mg} /$ $\mathrm{kg}$ for intravenous dose.

\section{Pharmacokinetic Study}

After dosing, blood samples of rats were serially collected from the caudal vein for determination of total radioactivity in plasma or collected from the abdominal aorta of each rat under ether anaesthesia for determination of unchanged drug in plasma. Plasma was obtained from the blood by centrifugation. Concentrations of total radioactivity or unchanged drug in the plasma were determined.

\section{Absorption Site Study}

The absorption of ${ }^{3} \mathrm{H}$-lamivudine from stomach, duodenum, jejunum and ileum was investigated in rats under ether anaesthesia. The both ends of stomach or designated sites of the small intestine were ligated and ${ }^{3} \mathrm{H}$-lamivudine was injected into each site of the digestive tract. The bile duct was ligated before injection into the site of small intestine. The ligated tracts were removed from rats immediately, 1 and 2 hours after injection. The tracts were washed by sterile saline to collect contents in the tracts and then they were homogenized. The absorption ratio was calculated by the following equation.

$$
\begin{aligned}
& \mathrm{AR}(\%)=(1-(\mathrm{RC}+\mathrm{RT}) / \mathrm{IR}) \times 100 \\
& \mathrm{AR}: \text { absorption ratio }(\%) \\
& \mathrm{RC}: \text { radioactivity in the contents } \\
& \mathrm{RT}: \text { radioactivity in the homogenate of digestive } \\
& \quad \text { tract } \\
& \mathrm{IR}: \text { radioactivity injected }
\end{aligned}
$$

\section{Urinary and Fecal Excretion}

Each rat was kept in a glass metabolism cage (Type
MC-ST; Sugiyamagen) after dosing of ${ }^{3} \mathrm{H}$-lamivudine and urine and feces were collected separately up to 168 hours. The urine was collected into containers cooled by ice. At the end of the collection period ( 168 hours post dose), rats were killed by ether anaesthesia and carcasses were obtained. Radioactivity in the urine, feces and carcasses was determined.

\section{Biliary Excretion Study}

Bile duct of each rat was cannulated with a polyethylene catheter under ether anaesthesia. Following recovery out of anaesthesia, rats were given ${ }^{3} \mathrm{H}$-lamivudine orally. The rats were kept in Bollman cages (Natsume Seisakusho) and bile, urine and feces were collected separately up to 48 hours after dosing. Radioactivity in the bile, urine and feces was determined.

\section{Determination of Radioactivity}

Aliquots of plasma, urine and bile were combusted using a sample oxidiser (Tri-carb 307; Canberra-Packard) in order to prepare samples for determination of radioactivity. Feces was homogenized with distilled water and aliquots of the homogenates were combusted by the sample oxidiser. Aliquots of gastro-intestinal contents and homogenates of digestive tracts were also combusted by the sample oxidiser. Carcasses were solubilized with $10 \%(\mathrm{w} / \mathrm{v})$ sodium hydroxide in $60 \%(\mathrm{v} / \mathrm{v})$ ethanolic solution. Aliquots of the carcass solution were incubated at $40^{\circ} \mathrm{C}$ after addition of hydrogen peroxide and mixed with liquid scintillator (Hionic fluor; Canberra-Packard). The radioactivity in each sample was determined using a liquid scintillation counter (Wallac 1410; Pharmacia) with automatic quench correction by an external standard method.

\section{Determination of Unchanged Drug in Plasma}

Concentrations of lamivudine in plasma were determined by HPLC after solid phase extraction. The plasma of rats receiving lamivudine was applied to the solid phase cartridge (LiChrolut SCX; Merck). Eluant from the cartridge was introduced onto an ODS column (LColumn; Chemicals Inspection and Testing Institute) 
and eluted by $8 \%(\mathrm{v} / \mathrm{v})$ methanol in $50 \mathrm{mM}$ phosphate-citrate buffer ( $\mathrm{pH} 7.5$ ) at a flow rate of $1 \mathrm{ml} / \mathrm{min}$. Lamivudine was detected by UV measurement $(270 \mathrm{~nm})$.

\section{Determination of Radioactive Components in Urine}

The urine of rats receiving ${ }^{3} \mathrm{H}$-lamivudine was analyzed by HPLC after filtration (Centricut V-MO 0.45 $\mu \mathrm{m}$; Kurabou). The filtrate was introduced onto an ODS column (Ultron VX-ODS; Shinwa Chemical Industries) and eluted by the gradient system between 10 $\mathrm{mM}$ potassium dihydrogenphosphate and $10 \%(\mathrm{v} / \mathrm{v})$ methanol in $10 \mathrm{mM}$ potassium dihydrogenphosphate at a flow rate of $1 \mathrm{ml} / \mathrm{min}$. Radioactivity was determined by a radioactive monitor (171 Radioisotope Detector; Beckman).

\section{Calculation of Pharmacokinetic Parameters}

The concentrations of total radioactivity in plasma were expressed as ng equivalents of lamivudine per $\mathrm{m} l$ of plasma. The half-lives $\left(t_{1 / 2}\right)$ on elimination phase after dosing were calculated by the least square method.
The area under the plasma concentration-time curve up to terminal measurement time $\left(\mathrm{AUC}_{(0-\mathrm{Tf})}\right)$ was calculated by the trapezoidal method and the $\mathrm{AUC}_{(0-\infty)}$ was expressed as the sum of the $\mathrm{AUC}_{(0-\mathrm{Tf})}$ and remaining area calculated by dividing the plasma level at terminal measurement time by an elimination rate constant. The oral clearance $\left(\mathrm{Cl}_{\mathrm{po}}\right)$ or total clearance $\left(\mathrm{Cl}_{\text {total }}\right)$ was calculated by dividing the dose by the $\mathrm{AUC}_{(0-\infty)}$. The mean residence time (MRT) was also calculated according to the trapezoidal method.

\section{Results}

1. Concentrations of Total Radioactivity in Plasma Mean concentrations of total radioactivity in plasma after a single oral administration of ${ }^{3} \mathrm{H}$-lamivudine to rats at a dose of $2 \mathrm{mg} / \mathrm{kg}$ are shown in Fig. 2 and calculated pharmacokinetic parameters are summarized in Table I.

After oral administration, the concentrations of total radioactivity in plasma reached the maximum of 328.1 ng eq. of lamivudine $/ \mathrm{m} l$ at 1.25 hours post dose in male rats and $321.0 \mathrm{ng}$ eq. $/ \mathrm{m} l$ at 1.38 hours post dose in fe-

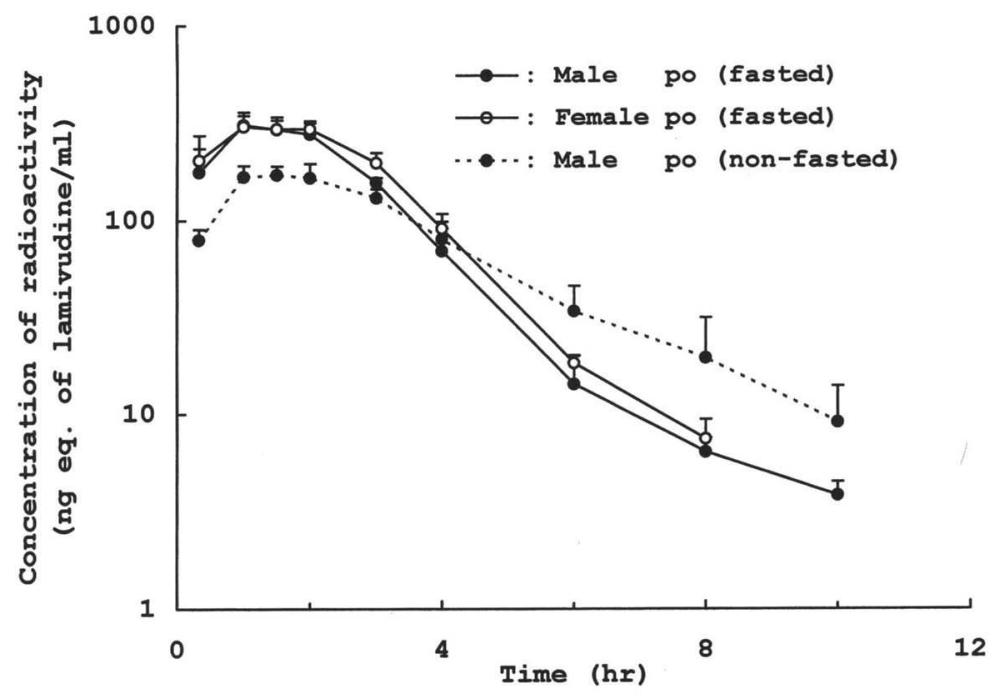

Fig. 2 Concentrations of total radioactivity in plasma after single oral administration of ${ }^{3} \mathrm{H}$-lamivudine to rats at a dose of $2 \mathrm{mg} / \mathrm{kg}$.

Data are expressed as the mean values \pm S.D. of four animals.

Table I Pharmacokinetic parameters of total radioactivity in plasma after single oral administration of ${ }^{3} \mathrm{H}$-lamivudine to rats at a dose of $2 \mathrm{mg} / \mathrm{kg}$

\begin{tabular}{lccc}
\hline & & Male & Female \\
\cline { 2 - 4 } \cline { 3 - 3 } & Fasted & Non-fasted & Fasted \\
\hline $\mathrm{T}_{\max }(\mathrm{hr})$ & $1.25 \pm 0.29$ & $1.75 \pm 0.29$ & $1.38 \pm 0.48$ \\
$\mathrm{C}_{\max }(\mathrm{ng}$ eq. $/ \mathrm{m} l)$ & $328.1 \pm 14.1$ & $177.4 \pm 22.5$ & $321.0 \pm 47.2$ \\
$\mathrm{t}_{1 / 2}(\mathrm{hr})$ & $2.23 \pm 0.45$ & $2.13 \pm 0.48$ & $1.54 \pm 0.17$ \\
$\mathrm{AUC}_{(0-\infty)}(\mathrm{ng}$ eq. $\cdot \mathrm{hr} / \mathrm{m} l)$ & $942 \pm 29$ & $745 \pm 50$ & $1043 \pm 107$ \\
$\mathrm{Cl}_{\mathrm{po}}(\mathrm{l} / \mathrm{hr} / \mathrm{kg})$ & $2.12 \pm 0.06$ & $2.69 \pm 0.18$ & $1.93 \pm 0.19$ \\
$\mathrm{MRT}(\mathrm{hr})$ & $2.34 \pm 0.12$ & $3.44 \pm 0.69$ & $2.36 \pm 0.0$ \\
\hline
\end{tabular}

Data are expressed as the mean values \pm S.D. of four animals. 
male rats. The concentrations declined rapidly with a half-life of 2.23 hours up to 10 hours post dose in male rats, and 1.54 hours up to 8 hours post dose in female rats. The $\mathrm{AUC}_{(0-\infty)}$ was 942 and $1043 \mathrm{ng}$ eq. $\cdot \mathrm{hr} / \mathrm{ml}$ in male and female rats, respectively.

In non-fasted male rats, the concentrations of total radioactivity in plasma reached the maximum of 177.4 ng eq. $/ \mathrm{m} l$ at 1.75 hours after oral administration and declined rapidly with a half-life of 2.13 hours up to 10 hours post dose. The $\mathrm{AUC}_{(0-\infty)}$ was $745 \mathrm{ng}$ eq. $\cdot \mathrm{hr} / \mathrm{ml}$.

\section{Concentrations of Lamivudine in Plasma}

Mean concentrations of unchanged drug in plasma after a single oral or intravenous administration of lamivudine to rats are shown in Fig. 3 and calculated pharmacokinetic parameters are summarized in Table II.

After oral administration of lamivudine at a dose of 2 $\mathrm{mg} / \mathrm{kg}$, the concentrations of lamivudine in plasma reached the maximum of $422.3 \mathrm{ng} / \mathrm{ml}$ at 1.00 hour post dose in male rats and $428.7 \mathrm{ng} / \mathrm{m} l$ at 0.33 hour post dose in female rats. The concentrations declined rapidly with a half-life of 0.78 hour up to 4 hours post dose in male rats, and 1.02 hour up to 6 hours post dose in female rats. The $\mathrm{AUC}_{(0-\infty)}$ was 1038 and $1086 \mathrm{ng} \cdot \mathrm{hr} / \mathrm{ml}$ in male and female rats, respectively.

After oral administration to male rats at a dose of 5 $\mathrm{mg} / \mathrm{kg}$, the concentrations of lamivudine in plasma reached the maximum of $1203.0 \mathrm{ng} / \mathrm{m} l$ at 0.33 hour post dose and declined rapidly with a half-life of 1.01 hour up to 6 hours post dose. The $\mathrm{AUC}_{(0-\infty)}$ was $2417 \mathrm{ng} \cdot \mathrm{hr} /$ $\mathrm{m} l$. After oral administration to male rats at a dose of 10 $\mathrm{mg} / \mathrm{kg}$, the concentrations of lamivudine in plasma reached the maximum of $1469.9 \mathrm{ng} / \mathrm{m} l$ at 1.00 hour post dose and declined rapidly with a half-life of 1.02 hour up to 10 hours post dose. The $\operatorname{AUC}_{(0-\infty)}$ was $4784 \mathrm{ng} \cdot \mathrm{hr} /$ $\mathrm{m} l$.

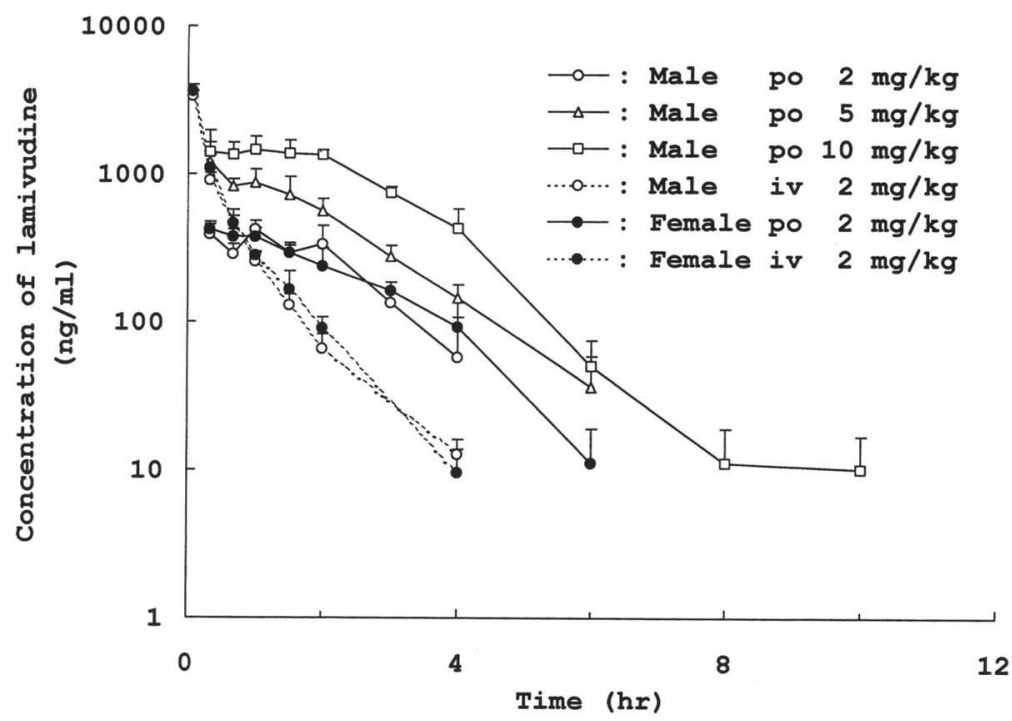

Fig. 3 Concentrations of unchanged drug in plasma after single oral or intravenous administration of non-labeled lamivudine to rats.

Data are expressed as the mean values \pm S.D. of four animals at each sampling point.

Table II Pharmacokinetic parameters of lamivudine in plasma after single oral or intravenous administration of lamivudine to rats

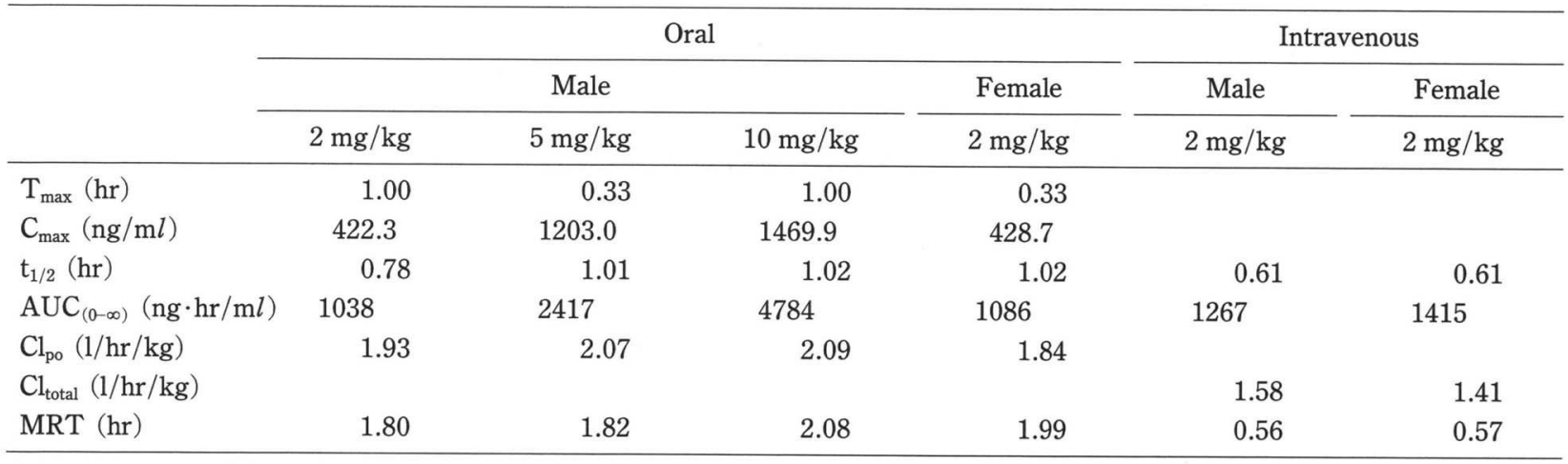

Data are calculated from the mean concentrations in plasma of four animals at each sampling point. 
After intravenous administration of lamivudine at a dose of $2 \mathrm{mg} / \mathrm{kg}$, the concentrations of lamivudine in plasma showed $3391.3 \mathrm{ng} / \mathrm{m} l$ in male rats and 3632.3 $\mathrm{ng} / \mathrm{m} l$ in female rats at the first sampling point, 5 minutes post dose. The concentrations declined rapidly with a half-life of 0.61 hours in both male and female rats, up to 4 hours post dose. The $\mathrm{AUC}_{(0-\infty)}$ was 1267 and $1415 \mathrm{ng} \cdot \mathrm{hr} / \mathrm{ml}$ in male and female rats, respectively.

\section{Absorption Site}

Absorption ratios of radioactivity in the different segments of gastrointestinal tract prepared in rats after injection of ${ }^{3} \mathrm{H}$-lamivudine at a dose of $2 \mathrm{mg} / \mathrm{kg}$ are shown in Table III.

The absorption ratio of radioactivity in stomach, duodenum, jejunum and ileum was 4.8\%, 66.4\%, 85.7\% and $47.9 \%$ of the dose, respectively, within 2 hours after injection.

\section{Urinary and Fecal Excretion}

Results of cumulative urinary and fecal excretion of total radioactivity after a single oral or intravenous ad- ministration of ${ }^{3} \mathrm{H}$-lamivudine to rats at a dose of $2 \mathrm{mg} /$ $\mathrm{kg}$ are shown in Table IV.

The ratio of excreted radioactivity in male and female rats was $69.3 \%$ and $74.1 \%$ of the dose in urine and $29.1 \%$ and $23.7 \%$ in feces, respectively, up to 168 hours after oral administration. The ratio of radioactivity in carcass at 168 hours post dose was $0.2 \%$ of the dose in male rats and $0.1 \%$ in female rats.

After intravenous administration to male rats, the ratio of excreted radioactivity was $93.9 \%$ of the dose in urine and $2.8 \%$ in feces up to 168 hours post dose. The ratio of radioactivity in carcass at 168 hours post dose was $0.1 \%$ of the dose.

The recovery of the cumulative amounts excreted after oral or intravenous administration of ${ }^{3} \mathrm{H}$-lamivudine to rats was more than $96.8 \%$ of the dose.

\section{Biliary Excretion}

Results of cumulative biliary excretion of total radioactivity after a single oral administration of ${ }^{3} \mathrm{H}$-lamivudine to male rats at a dose of $2 \mathrm{mg} / \mathrm{kg}$ are shown in Table $\mathbf{V}$.

The ratio of excreted radioactivity in bile was $0.8 \%$ of the dose up to 48 hours after oral administration. Urina-

Table III Absorption ratios of radioactivity in the different segments of gastrointestinal tract prepared in rats after injection of ${ }^{3} \mathrm{H}$-lamivudine at a dose of $2 \mathrm{mg} / \mathrm{kg}$

\begin{tabular}{ccccc}
\hline \multirow{2}{*}{$\begin{array}{c}\text { Time after } \\
\text { injection }\end{array}$} & Stomach & Duodenum & Jejunum & Ileum \\
\cline { 2 - 5 } & $1.4 \pm 1.2$ & $3.3 \pm 1.4$ & $1.4 \pm 1.0$ & $3.2 \pm 0.8$ \\
\hline $0 \mathrm{hr}$ & $3.6 \pm 2.1$ & $41.4 \pm 9.5$ & $54.8 \pm 13.0$ & $31.4 \pm 12.3$ \\
$1 \mathrm{hr}$ & $4.8 \pm 3.0$ & $66.4 \pm 10.7$ & $85.7 \pm 8.8$ & $47.9 \pm 10.5$ \\
\hline
\end{tabular}

Data are expressed as the mean values \pm S.D. of three animals.

$0 \mathrm{hr}$ : immediately after injection.

Table IV Cumulative excretions of radioactivity in urine and feces after single oral or intravenous administration of ${ }^{3} \mathrm{H}$-lamivudine to rats at a dose of $2 \mathrm{mg} / \mathrm{kg}$

\begin{tabular}{|c|c|c|c|c|c|c|c|c|c|}
\hline \multirow{4}{*}{ Time(hr) } & \multicolumn{9}{|c|}{ Excretion of radioactivity ( $\%$ of dose) } \\
\hline & \multicolumn{6}{|c|}{ Oral } & \multicolumn{3}{|c|}{ Intravenous } \\
\hline & \multicolumn{3}{|c|}{ Male } & \multicolumn{3}{|c|}{ Female } & \multicolumn{3}{|c|}{ Male } \\
\hline & Urine & Feces & Total & Urine & Feces & Total & Urine & Feces & Total \\
\hline $0-10$ & $65.0 \pm 4.6$ & - & $65.0 \pm 4.6$ & $69.0 \pm 9.1$ & - & $69.0 \pm 9.1$ & $90.7 \pm 4.3$ & - & $90.7 \pm 4.3$ \\
\hline 24 & $68.3 \pm 5.4$ & $28.0 \pm 5.9$ & $96.2 \pm 0.8$ & $72.9 \pm 9.7$ & $21.9 \pm 10.5$ & $94.7 \pm 2.6$ & $93.3 \pm 1.9$ & $2.5 \pm 0.4$ & $95.8 \pm 2.1$ \\
\hline 48 & $68.8 \pm 5.5$ & $29.0 \pm 5.8$ & $97.7 \pm 1.0$ & $73.8 \pm 10.2$ & $23.6 \pm 9.2$ & $97.4 \pm 1.5$ & $93.7 \pm 1.9$ & $2.7 \pm 0.4$ & $96.4 \pm 2.1$ \\
\hline 72 & $68.9 \pm 5.6$ & $29.0 \pm 5.8$ & $97.9 \pm 0.9$ & $74.0 \pm 10.2$ & $23.7 \pm 9.1$ & $97.7 \pm 1.5$ & $93.8 \pm 1.9$ & $2.7 \pm 0.4$ & $96.5 \pm 2.1$ \\
\hline 96 & $69.1 \pm 5.7$ & $29.0 \pm 5.8$ & $98.2 \pm 0.6$ & $74.0 \pm 10.2$ & $23.7 \pm 9.1$ & $97.7 \pm 1.5$ & $93.8 \pm 1.9$ & $2.8 \pm 0.4$ & $96.6 \pm 2.0$ \\
\hline 120 & $69.2 \pm 5.8$ & $29.1 \pm 5.8$ & $98.3 \pm 0.5$ & $74.0 \pm 10.2$ & $23.7 \pm 9.1$ & $97.8 \pm 1.5$ & $93.9 \pm 1.9$ & $2.8 \pm 0.5$ & $96.7 \pm 1.9$ \\
\hline 144 & $69.2 \pm 5.8$ & $29.1 \pm 5.8$ & $98.3 \pm 0.5$ & $74.0 \pm 10.2$ & $23.7 \pm 9.1$ & $97.8 \pm 1.5$ & $93.9 \pm 1.9$ & $2.8 \pm 0.5$ & $96.7 \pm 1.9$ \\
\hline 168 & $69.3 \pm 5.8$ & $29.1 \pm 5.8$ & $98.3 \pm 0.5$ & $74.1 \pm 10.2$ & $23.7 \pm 9.1$ & $97.8 \pm 1.5$ & $93.9 \pm 1.9$ & $2.8 \pm 0.5$ & $96.7 \pm 1.9$ \\
\hline Carcass & & $0.2 \pm 0.0$ & & & $0.1 \pm 0.1$ & & & $0.1 \pm 0.0$ & \\
\hline
\end{tabular}

Data are expressed as the mean values \pm S.D. of four animals —: Not determined. 
Table V Cumulative excretions of radioactivity in bile, urine and feces after single oral administration of ${ }^{3} \mathrm{H}-$ lamivudine to bileduct cannulated male rats at a dose of $2 \mathrm{mg} / \mathrm{kg}$

\begin{tabular}{ccccc}
\hline \multirow{2}{*}{ Time $(\mathrm{hr})$} & \multicolumn{4}{c}{ Excretion of radioactivity (\% of dose) } \\
\cline { 2 - 4 } & Bile & Urine & Feces & Total \\
\hline $0-3$ & $0.4 \pm 0.2$ & - & - & $0.4 \pm 0.2$ \\
6 & $0.7 \pm 0.2$ & $47.7 \pm 13.7$ & - & $48.4 \pm 13.8$ \\
24 & $0.8 \pm 0.2$ & $81.0 \pm 16.5$ & $16.6 \pm 13.9$ & $98.4 \pm 3.2$ \\
48 & $0.8 \pm 0.2$ & $81.6 \pm 16.1$ & $18.8 \pm 15.9$ & $101.2 \pm 1.0$ \\
\hline
\end{tabular}

Data are expressed as the mean values \pm S.D. of five animals. - : Not determined.

ry and fecal excretion accounted for $81.6 \%$ and $18.8 \%$ of the dose, respectively, up to 48 hours post dose.

\section{Radio-HPLC Analysis of Urine}

Results of radio-HPLC analysis of urinary samples collected from rats after a single oral or intravenous administration of ${ }^{3} \mathrm{H}$-lamivudine at a dose of $2 \mathrm{mg} / \mathrm{kg}$ are summarized in Table VI and a representative radioHPLC chromatogram of the urinary sample is shown in Fig. 4.

Most of radioactivity in the urine collected from rats up to 24 hours after oral administration was corresponding to lamivudine, accounting for $65.7 \%$ of the dose in male rats and $70.7 \%$ in female rats. A little radioactive component corresponding to trans-sulphoxide of lamivudine (GI138870X) was also observed, accounting for $2.0 \%$ of the dose in male rats and $1.1 \%$ in female rats.

Only two radioactive components corresponding to lamivudine and GI138870X were also observed in the urine collected from male rats up to 24 hours after intravenous administration, accounting for $89.5 \%$ and $3.2 \%$ of the dose, respectively.
Table VI Composition of lamivudine and its metabolites in urine after single oral or intravenous administration of ${ }^{3} \mathrm{H}$-lamivudine to rats at a dose of $2 \mathrm{mg} / \mathrm{kg}$

\begin{tabular}{|c|c|c|c|c|}
\hline & & \multirow{2}{*}{ Time $(h r)$} & \multicolumn{2}{|c|}{$\begin{array}{l}\text { Radioactivity in urine } \\
(\% \text { of dose })\end{array}$} \\
\hline & & & Lamivudine & GI138870X \\
\hline \multirow[t]{6}{*}{ Oral } & Male & $0-10 \mathrm{hr}$ & $62.6 \pm 4.2$ & $1.9 \pm 0.9$ \\
\hline & & $10-24 \mathrm{hr}$ & $3.1 \pm 1.3$ & N.D. \\
\hline & & $(0-24 \mathrm{hr})$ & $65.7 \pm 4.9$ & $2.0 \pm 0.8$ \\
\hline & Female & $0-10 \mathrm{hr}$ & $67.1 \pm 8.7$ & $1.1 \pm 0.6$ \\
\hline & & $10-24 \mathrm{hr}$ & $3.7 \pm 1.8$ & N.D. \\
\hline & & $(0-24 \mathrm{hr})$ & $70.7 \pm 9.3$ & $1.1 \pm 0.6$ \\
\hline \multirow{3}{*}{$\begin{array}{l}\text { Intra- } \\
\text { venous }\end{array}$} & Male & $0-10 \mathrm{hr}$ & $87.1 \pm 4.3$ & $3.0 \pm 1.4$ \\
\hline & & $10-24 \mathrm{hr}$ & $2.4 \pm 2.4$ & N.D. \\
\hline & & $(0-24 \mathrm{hr})$ & $89.5 \pm 2.3$ & $3.2 \pm 1.2$ \\
\hline
\end{tabular}

Data are expressed as the mean values \pm S.D. of four aminals. N.D. : Not detected.

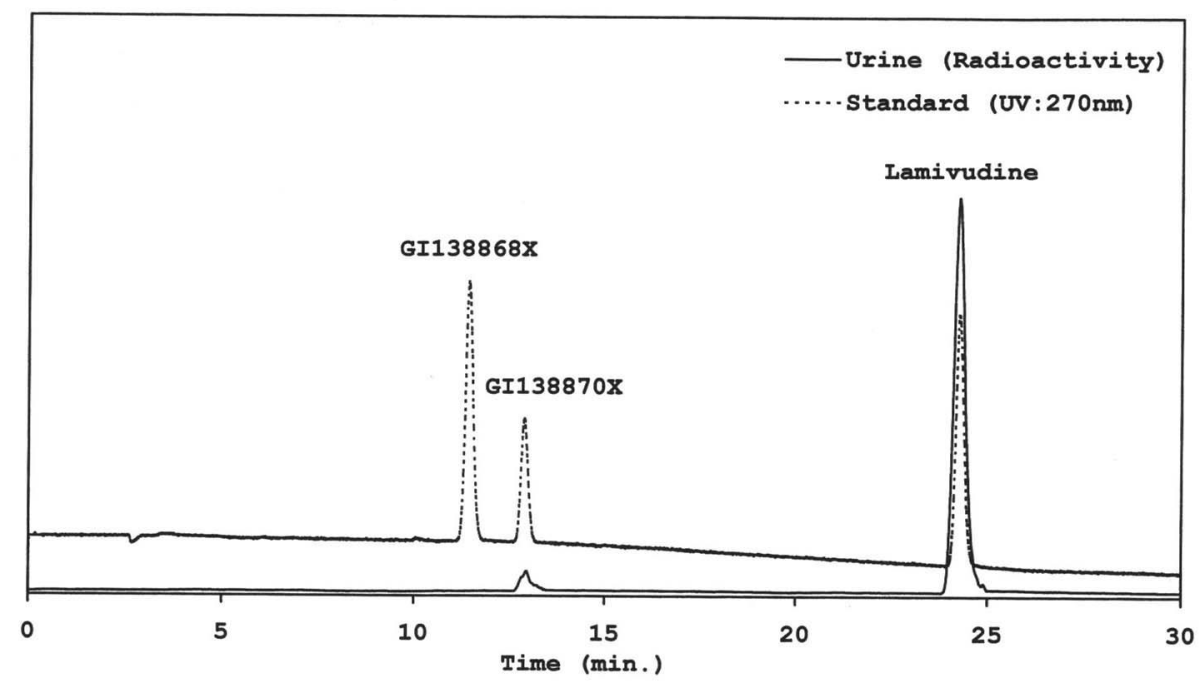

Fig. 4 Representative radio-HPLC chromatogram of urine collected during the first 10 hour after single oral administration of ${ }^{3} \mathrm{H}$-lamivudine to male rats at a dose of $2 \mathrm{mg} / \mathrm{kg}$. 


\section{Discussion}

In this study, the absorption, metabolism and excretion of lamivudine were investigated after a single oral administration of ${ }^{3} \mathrm{H}$-lamivudine to rats at a dose of 2 $\mathrm{mg} / \mathrm{kg}$.

The concentrations of total radioactivity in plasma reached the maximum at about 1 hour after oral administration of ${ }^{3} \mathrm{H}$-lamivudine and declined with a half-life of about 2 hours. These results indicate that lamivudine would be absorbed quickly after oral administration and also eliminated rapidly from plasma. Comparing the plasma kinetics of total radioactivity after oral administration to fasted and non-fasted rats, the $\mathrm{C}_{\max }$ and $\mathrm{AUC}_{(0-\infty)}$ in non-fasted rats was $54 \%$ and $79 \%$ of that in fasted rats, respectively. It is suggested that feeding would depress the absorption of lamivudine during a early period after oral dosing but not remarkably decrease the amount of absorbed lamivudine.

Based on the $\mathrm{AUC}_{(0-\infty)}$ of unchanged drug after oral and intravenous administration, bioavailability was estimated at about $80 \%$, indicating high bioavailability of lamivudine after oral administration. After oral administration of lamivudine at a dose of 2,5 and $10 \mathrm{mg} / \mathrm{kg}$, $\mathrm{C}_{\max }$ raised in proportion to the increase of dose level and significant linearity was observed between the dose levels and $\mathrm{AUC}_{(0-\infty)}$ of lamivudine. Moreover, the $\mathrm{Cl}_{\mathrm{po}}$ is about $21 / \mathrm{hr} / \mathrm{kg}$ at the dose levels. The plasma kinetics of lamivudine seems to be similar within the dose levels.

After injection of ${ }^{3} \mathrm{H}$-lamivudine to the different segments of gastro-intestinal tract, the absorption ratio of radioactivity was very low at stomach but about 50 to $85 \%$ at each site of small intestine, duodenum, jejunum and ileum. This finding indicates that lamivudine would be mainly absorbed at whole area of small intestine after oral administration.

About $70 \%$ and $90 \%$ of the dosed radioactivity was excreted into urine up to 24 hours after oral and intravenous administration of ${ }^{3} \mathrm{H}$-lamivudine, respectively. On the other hand, radioactivity was scarcely excreted into bile after oral administration. These findings indicate that most absorbed lamivudine would be excreted into urine rapidly and completely and some unabsorbed lamivudine would be excreted into feces. Based on the ratios of urinary excretion after oral and intravenous administration to male rats, the fraction of drug absorbed was estimated $74 \%$, indicating much lamivudine would be easily absorbed after oral administration.

The radio-HPLC analysis of urine collected from rats after oral or intravenous administration of ${ }^{3} \mathrm{H}$-lamivudine indicates that most radioactivity in urine would be corresponding to lamivudine. Absorbed lamivudine would be mainly excreted into urine as above-mentioned. These findings suggest that absorbed lamivudine would be scarcely metabolized and mainly excreted into urine as unchanged drug.

Remarkable difference of all the data was not observed between male and female rats in this study, indicating no sex-related difference in the metabolic fate of lamivudine in rats.

In conclusion, it was observed in this study that lamivudine would be absorbed quickly and smoothly from small intestine after oral administration to rats, and absorbed lamivudine would be scarcely metabolized, and excreted rapidly and completely into urine.

\section{References}

1) Coates, J. A. V., Cammack, N., Jenkinson, H. J., Jowett, A. J., Jowett, M. I., Pearson, B. A., Penn, C. R., Rouse, P. L., Viner, K. C. and Cameron, J. M.: (-)-2'-Deoxy-3'-thiacytidine is a potent, highly selective inhibitor of human immunodeficiency virus type 1 and type 2 replication in vitro. Antimicrob. Agents. Chemother., 36(4): 733-739 (1992).

2) Hart, G. J., Orr, D. C., Penn, C. R., Figueiredo, H. T., Gray N. M., Boehme, R. E. and Cameron, J. M.: Effects of (-)2 -deoxy-3'-thiacytidine (3TC) 5 '-triphosphate on human immunodeficiency virus reverse transcriptase and mammalian DNA polymerase alpha, beta, and gamma. Antimicrob. Agents. Chemother., 36(8): 1688-1694 (1992).

3) Doong, S., Tsai, C., Schinazi, R. F., Liotta, D. C. and Cheng, Y.: Inhibition of the replication of hepatitis $\mathrm{B}$ virus in vitro by $2^{\prime}, 3^{\prime}$-dideoxy- $3^{\prime}$-thiacytidine and related analogues. Proc. Natl. Acad. Sci. USA, 88: 8495-8499 (1991).

4) Chang, C., Doong, S., Zhou, J. H., Beach, J. W., Jeong, L. S., Chu, C. K., Tsai, C. and Cheng, Y.: Deoxycytidine deaminase-resistant Stereoisomer is the active form of $( \pm)$ $-2^{\prime}, 3^{\prime}$-dideoxy $-3^{\prime}$-thiacytidine in the inhibition of hepatitis B virus replication. J. Biol. Chem., 267 (20): 13938-13942 (1992). 